\title{
Simulation and Analysis of Main Steam Control System Based on Heat Transfer Calculation
}

\author{
Zhenqun HUANG ${ }^{1}$, Ruyan $\mathrm{LI}^{1}$ ， Zhongbao FENG ${ }^{1}$, Songhan Wang ${ }^{1}$, \\ Wenbo $\mathrm{LI}^{2, \mathrm{a}}$,Jiwei CHENG ${ }^{2, \mathrm{~A}}$, Yingai $\mathrm{JIN}^{2}$ \\ ${ }^{1}$ Jilin Province Electric Power Science Research Institute Co., Ltd, Changchun , 130021, China \\ ${ }^{2}$ College of Automotive Engineering, Jilin University, Changchun, Jilin, 130022, China \\ a)Corresponding author:694833871@qq.com \\ a)Corresponding author:13194357717
}

\begin{abstract}
In this paper, after thermal power plant 300MW boiler was studied, matlab was used to write calculation program about heat transfer process between the main steam and boiler flue gas and a mount of water was calculated to ensure the main steam temperature keeping in target temperature. Then heat transfer calculation program was introduced into simulink simulation platform based on control system multiple models switching and heat transfer calculation. The results show that multiple models switching control system based on heat transfer calculation not only overcome the large inertia of main steam temperature, a large hysteresis characteristic of main steam temperature, but also adapted to the boiler load changing.
\end{abstract}

Key words: main steam; target temperature; heat transfer calculation

\section{INTRODUCTION}

The main object of this paper is comparing the advantages and disadvantages of two methods of controlling main steam temperature. The first method is named PID, PID controller is proportion、 integration 、 differentiation controller. The second method is J-PID, which is the traditional PID controller based on heat transfer calculation. The overall simulation scheme is as follows: the first step of the simulation is calculating two control systems PID and J-PID under different load conditions, then the simulation results are compared. We have given the basis of choosing J-PID control system instead of PID control in this paper. At last, we took on the simulation under three typical conditions.

\section{SYSTEM DIAGRAMS AND TRANSFER FUNCTION OF PID}

The simulation model of PID main steam temperature control system is set up under the load of thirty percent boiler and the control objects are the functions of anterior region and inert zone. The system was put at last of the paper as figure 1 and 2 .

The following is the optimal parameters of the optimized PID controller, including the rise time, 
overshoot, peak time, adjustment time.

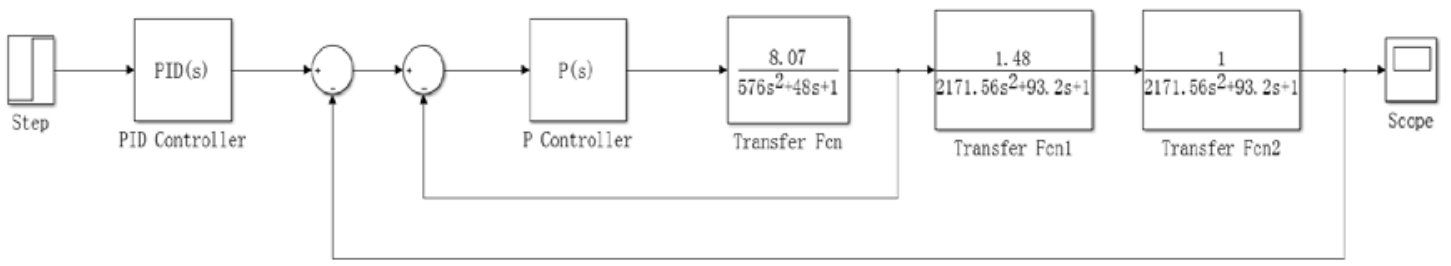

Fig.1 PID control system of main steam temperature under 30\% load condition

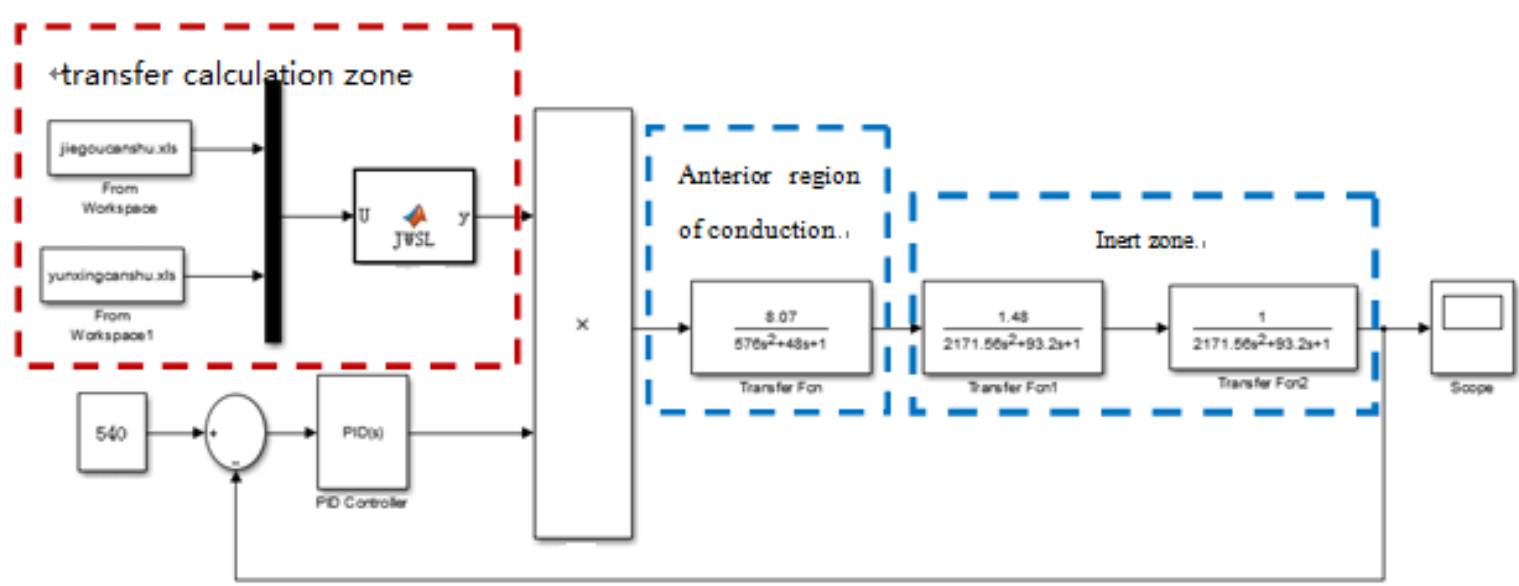

Fig.2 Main steam temperature control system based on heat transfer calculation under 30\% load condition

\begin{tabular}{|c|c|c|c|}
\hline \multicolumn{4}{|l|}{ Controller Parameters } \\
\hline & Tuned & Block & \\
\hline p & 1.0965 & 1.0965 & A \\
\hline I & 0.0057136 & 0.0057136 & $\equiv$ \\
\hline D & 51.9314 & 51.9314 & - \\
\hline N & 1.1193 & 1.1193 & - \\
\hline \multicolumn{4}{|c|}{ Performance and Robustness } \\
\hline & Tuned & Block & \\
\hline Rise time & 119 seconds & 119 seconds & \\
\hline Settling time & 549 seconds & 549 seconds & \\
\hline Overshoot & $0 \%$ & $0 \%$ & \\
\hline Peak & 0.998 & 0.998 & \\
\hline Gain margin & $11.6 \mathrm{~dB} @ 0.0311 \mathrm{rad} / \mathrm{s}$ & $/ \mathrm{s} 11.6 \mathrm{~dB} @ 0.0311 \mathrm{rad}$. & \\
\hline Phase margin & 75 deg@0.00979 ra... & .. 75 deg @ 0.00979 ra.. & \\
\hline Closed-loop stability & Stable & Stable & \\
\hline
\end{tabular}

Fig. 3 Optimal parameters and indexes of PID main steam temperature controller

\section{SYSTEM DIAGRAMS AND TRANSFER FUNCTION OF J-PID}

The following is the optimal parameters of the optimized J-PID controller, including the rise time, overshoot, peak time, adjustment time. 


\begin{tabular}{|l|l|l|}
\hline Controller Parameters & \multicolumn{2}{l|}{} \\
\hline \multicolumn{1}{|l|}{} & Tuned & Block \\
\hline P & 1.3265 & 1.3265 \\
\hline I & 0.0085317 & 0.0085317 \\
\hline N & 51.0143 & 51.0143 \\
\hline N & 1.4091 & 1.4091 \\
\hline
\end{tabular}

Fig. 4 Optimal parameters and indexes of J-PID main steam temperature controller

\section{SIMULATION ANALYSIS}

The simulation model of PID and J-PID main steam temperature control system under 30\% load conditions is given in the above description. In this section, the simulation of two main steam temperature control systems under 3 typical load conditions is carried out. The results are as follows:

(1) The simulation results of the two control systems under $30 \%$ load conditions are as follows:

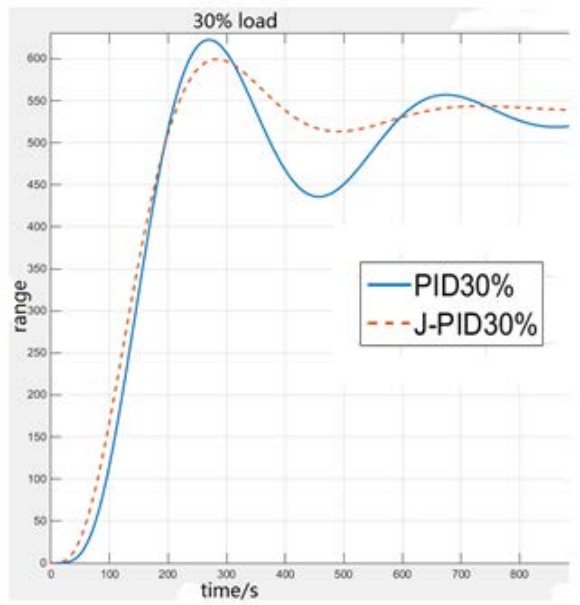

Fig.5 Comparison of control effects under 30\% load conditions

(2) The simulation results of the two control systems under $100 \%$ load conditions are as follows:

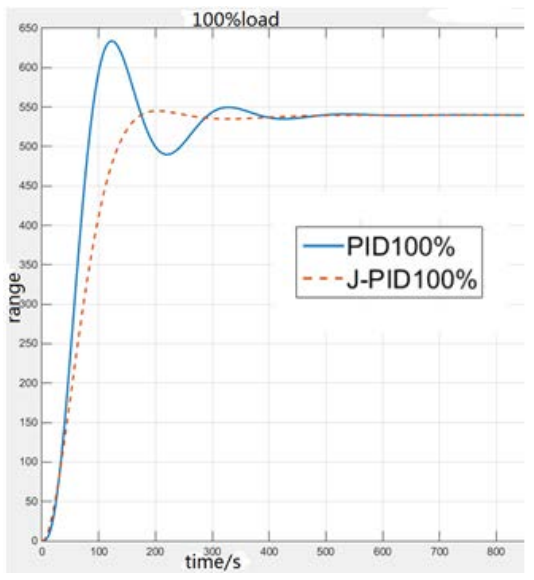

Fig.6 Comparison of control effects under 100\% load conditions

The simulation curves show that when the boiler operates under $30 \%$ and $44 \%$ load conditions, 
the temperature of the main steam is realized as large inertia and large lag and the system has a large response time, so the main steam temperature takes a long time to reach a steady state. Compared with the PID control system, the overshoot of the J-PID control system is very small. What's more, the larger the load, the smaller the overshoot. At last when the boiler operates at 100\% load, the J-PID has almost no overshoot.

\section{CONCLUSIONS}

The control effect of the main steam temperature control system based on heat transfer calculation is better than that of PID, the main reason is that the J-PID system can eliminate the disturbance of the system quickly (such as main steam flow, temperature, flue gas flow rate, temperature ).

\section{ACKNOWLEDGEMENTS}

The project [Improving the Combustion Mode and Security Running Control Strategy to Decrease the Pollution in Northeast of China (UK-CIAPP\201) ] was supported by the Royal Academy of Engineering under the UK-China Industry Academia Partnership Programme scheme. The authors are grateful for the support of the Royal Academy of Engineering and the UK government's Newton Fund.

This work was supported by project “Analysis of main steam control system based on heat transfer calculation, No. :S G T Y H T/16-JS-198”

\section{REFERENCES}

[1] Jin,X,Sun,J.,Liu,J.,etal.DesignofadaptiveintemalmodelformainsteamtemPeraturecontrolsystembas edonsingleneuron.in:Sun,J.,editor. Intelligent Control and Automation, 2004.WCICA 2004.Fifth World Congress on:vol.4, 2004. 3560-3564, Vol.3564.

[2] Zhi-Ming,Q.,Luan-Ying,2.,Jun-Jie,G,etal.Single-neuron PSD adaptive control based-on Smith predictor for the main temperature. in: Luan -Ying, Z, editor. Machine Learing and Cybernetics, 2004. Proceedings of 2004 International Conference on: Vol.2,2004. 1088 -1092, Vol.1082.

[3] Kalogirou, S.A. Artificial intelligence for the modeling and control of combustion processes: a review. Progress in Energy and Combustion Science. 2003, 29(6): 515 -566.

[4] Kocaarslan, Cam, E. An adaptive control application in a large thermal combined Power Plant. Energy Conversion and Management. 2007,48(1):174-183

[5] Docquier, N., Candel, S. Combustion control and sensors: a review. Progress in Energy and Combustion Science.2002, 28(2):107-150. 